\title{
Benchmarking Study of West Africa's Offshore Support Ship Building and Repair Capability
}

\author{
Chinedum Onyemechi ${ }^{1 *}$, Chinemerem Igboanusi ${ }^{2}$, Anthony Ezenwa ${ }^{2}$ and Abiodun Sull ${ }^{3}$ \\ ${ }^{1}$ Department of Maritime Management Technology, Federal University of Technology, Nigeria \\ ${ }^{2}$ Department of Transport Management Technology, Federal University of Technology, Nigeria \\ ${ }^{3}$ Federal College of Fisheries and Marine Technology, Nigeria
}

Submission: August 11, 2020; Published: September 28, 2020

Corresponding author: Chinedum Onyemechi, Department of Maritime Management Technology, Federal University of Technology Owerri, Nigeria

\begin{abstract}
The work surveyed current position of most West African Ship building outfits through a benchmark study of the building and repair capabilities of these yards vis a' vis the offshore ocean oil and gas production subsector and posed a great need for massive investments derived from well-established methods like, diamond model. Recommended solutions include immediate revitalization of research on the subject areas of Ocean technology and Naval Architecture. Pathways for quick realization of this objective were based on

the evolution of a new industry to academic model that draws from local content experience of advanced countries ocean technology ecosystem. An analysis of Nigeria's shipbuilding drive was made using existing facilities in her shipyard sector. Application of assembly line system and the modular methods were analyzed to determine best techniques given existing facilities in the region. Benchmark study of the entire sector was made evolving new policy directions for the region's rich oil sector.
\end{abstract}

Keywords: Security patrol vessels; Platform supply vessels; Line Handling Tug; Anchor Handling Tug; Crew Boats; Ocean technology

\section{Introduction}

The West African ship building and ship repair space is dominated by shipyards most of which are govern men $t$ owned. However, few private owned companies have joined them recently as seen in Nigeria. This development may have arisen due to innovations by new local content regulations emerging in the region. Local content regulations demand vessels supporting the oil and gas sector in the region to be built and repaired in the region before seeking for outside shipyards, thus preserving business for local operators first before others. Good measures of developments have occurred in most West African shipyards based on local content. However, the acquisitions of basic ship building skills as well as shipyard management skills still stand as barrier to development. The implications are that most of the vessels operating in the region still go outside the region to effect repairs.

\section{Objective}

This work seeks to assess through the instrument of benchmarking he output of most West African shipyards vis a' vis their contribution to shipbuilding and repair in the offshore sector of the region.

\section{Literature Review}

The global market structure of offshore support vessels as reported by Clarkson shows the market for offshore support vessels is suffering from overcapacity due to the recent increase in the construction of small vessels in Asia and very large vessels for the North Sea and Brazilian markets. This is because of the large order book for platform support vessels (PSVs) that has been driven by speculative orders and represents around $40 \%$ of the fleet. The implications are order book cancellations. Clarkson [1] Douglas-Westwood on his own opined applying maximum tonnage of each yard that $34 \%$ of OECD yards are able to construct production units such as floating production, storage and offloading (FPSO) and 48\% are able to produce drill ships [2]. Using the process of iteration he concluded that $96 \%$ of yards are able to produce smaller and less complicated vessels such as offshore support vessels while observing that, not all yards have 
the engineering, procurement and construction capabilities to produce offshore ships [3].

\section{Methodology}

The study was based on ground assessment of shipyard infrastructure in the region as well as existing database of shipyard activities found by search engine. Data Envelopment Analysis of West Africa's shipyard sector was also carried out using dry-dock capacity and floating dock capacity as inputs while percentage of Tanker ship repairs and Offshore Support vessel repairs formed in selected major yards formed the inputs.

\section{Finding: Gap Analysis of Nigeria's Shipyard Sector}

An overview of layout shows complete absence of standard shipbuilding culture and practices set out since the revolution of shipyards started in the Arendal shipyard decades ago when assembly line system was introduced into shipyard management. The essence of a layout will further prevent any shipbuilding revolution from kicking off in the sub sector. Modular production now key areas in European shipyards are still absent from the Nigerian shipbuilding scenario. An important basic beginning will thus be the set -up of a massive benchmarking of all Nigerian Shipyards to be supervised by the Shipping and Logistics group of Nigerian Content Consultative forum led by qualified professionals knowledgeable in the field. The benchmarking process should thus follow approved standards used by developed nations in a view to revolutionizing the productivity of the Nigerian Shipbuilding sector.

An attempt to classify the Nigerian Shipbuilding sector evidently reveals the following main sectors, first are the niche corporations with standard facilities for ship maintenance who service international ships calling at Lagos. Under this category, one will include, Niger-dock with a graving dry dock capacity to handle 25000-ton vessel. No other shipyard in the country is built to capacity. The second closest to it is the SHI/MCE shipyard hosted by LADOL built specifically for topside integration of Floating Production Storage and Offloading facilities FPSOs now operative in Nigeria's offshore to Nigerian Local Content laws which made it compulsory to make such topside integration in Nigeria. The like of this class is expected to be built in Badagry Lagos in NO distant time coming from the local content contribution of SAMSUNG / NLNG awarded contract.

Besides the above shipyards which we have classified as niche shipyards are the emerging marine technology shipbuilding sector. This sector comprises of new entrants into Nigeria's shipbuilding sector who are also products of Nigeria's local content laws. Prior to the emergence of Nigeria's local content ship categorization laws, the emerging shipbuilding sector has been characterized by operational dormancy due to absence of necessary contracts to support the sector. However, since the introduction of this regulation, in a bid to be classified as Class AAA vessel built and owned by Nigerians, an emerging marine technology pulled ship building sector is on the rise. These are characterized by absence of ship building facilities yet achieving shipbuilding milestones with non-benchmarked facilities.

There is strong absence of standard ship building cultures and practices as found in modern shipyards in these yards. To make progress, the sector must sponsor a vigorous shipyard benchmarking study to bridge the existing gaps and close such gaps to meet up with available standards worldwide, encourage study of Naval Architecture and Maritime Technology courses in Nigerian universities as well as encourage oil and gas companies to invest in Marine hydrodynamic research laboratories for effective offshore management of facilities in the entire maritime cluster and technology ecosystem.

\section{Forecast Diagnostics of Nigerian Shipbuilding}

NCDMB [4] opined that current NIMASA shipyard capacity audit should take into consideration the types of vessels in demand within Nigerian waters and develop interventions that will lead to the establishment or upgrade of shipyards with the following attributes: 1 . Tier 3 yards -Capacity to fully construct category 1 vessels and maintain other types of vessels 2 . Tier 2 yards- capacity to fully construct category 1 vessels, integrate top side of category 2 vessels, and maintain other types of vessels 3 . Tier 1 yards- capacity to fully construct categories 1 and 2 vessels, integrate top side of category 3 vessels and maintain other types of vessels NIMASA Q1 2019 Vessel maintenance history will continue to be a major criteria in the harmonized NCDMBNIMASA marine vessel categorization procedure.

\section{Nigeria's Offshore Supply Vessel Projections 2014- 2018}

Findings from NCDMB (2018) show that top 5 vessels utilized in Nigeria for the 2014 to 2018 year ended were Security Patrol Vessels (SPV), Platform Supply Vessels (PSV), Line Handling Tug (LHT), Anchor Handling Tug (AHT), Crew Boats (CB) 2. The 5 vessels accounted for $49 \%$ of vessels utilized. Also top 5 in projected demand will be Various barges (VB), Tugboats (TB), Security Patrol Vessels (SPV), Jack up barges (JUB) and Crew Boats (CB). 2. The 5 account for $66 \%$ of vessels that will be required. Water Bus (WB), Support Vessel (SUV) are among the vessels that will be least demanded Category 1 vessels were more in demand accounting for $53 \%$ of vessels utilized. Furthermore, category 2 vessels accounted for $34 \% 3$. Vessels in category 3 accounted for $12 \%$ of vessels utilized. Vessels in Category 1 and 2 accounted for $87 \%$ of vessels utilized in the period 2014-2018 Volume of transaction for Category 1 vessels will be higher (49\%), compared to categories $2(23 \%)$ and category $3(28 \%)$. Vessels in Category 1 and 2 account for $72 \%$ of vessels that will be in demand over the period 2019-2023.

\section{Productivity of Major West African Shipyards}

The analysis below shows output productivity of selected major shipyards in the West AFRICAN sub region. Analyzed in 
the work includes PSC Team shipyard in Ghana, Nigeria's Nigerdock and Dakar Nave floating dock, Senegal (Figure 1). The above refers to Team shipyard in Ghana, an oil producing nation with a floating production storage and offloading FPSO vessel operating offshore. The country also has several offshore support vessels in operation visiting Team shipyard other West African shipyards for repair when needed. Team shipyard has the largest dry dock facility in the region, though it must improve her repair capability (Figure 2).

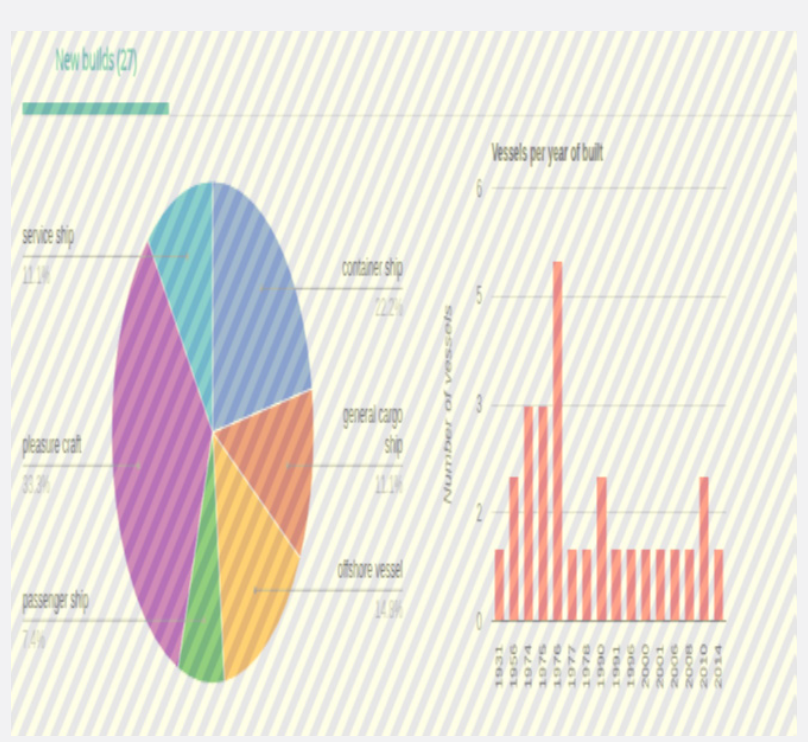

Figure 1: Productivity of Team Shipyard, Ghana.

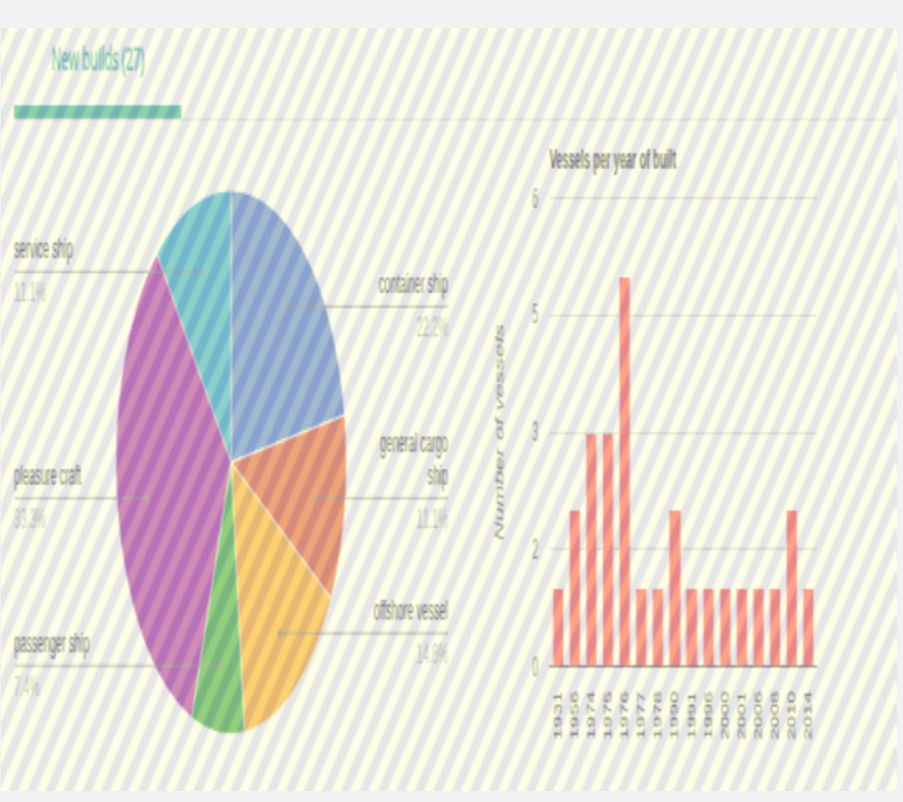

Figure 2: Productivity of Niger dock, Nigeria.

The company Niger-dock is the Nigeria's major shipyard handling the construction of offshore marine jackets for Nigeria's offshore support sector. Most major Independent oil companies in Nigeria like ExxonMobil, Shell Nigeria Exploration and Petroleum Company etc. form major client s to the Niger-dock shipyard. Recently a private shipyard by name LADOL was built in the same region handling top side integration of a major FPSO by Total Nigeria Plc through Samsung Heavy Industries and MCE. The capacity of the yard is still inadequate compared to the number of FPSOs and offshore support vessels in the region who still leave the nations shores in search of repairs in other shipyards. (Figure 3) 


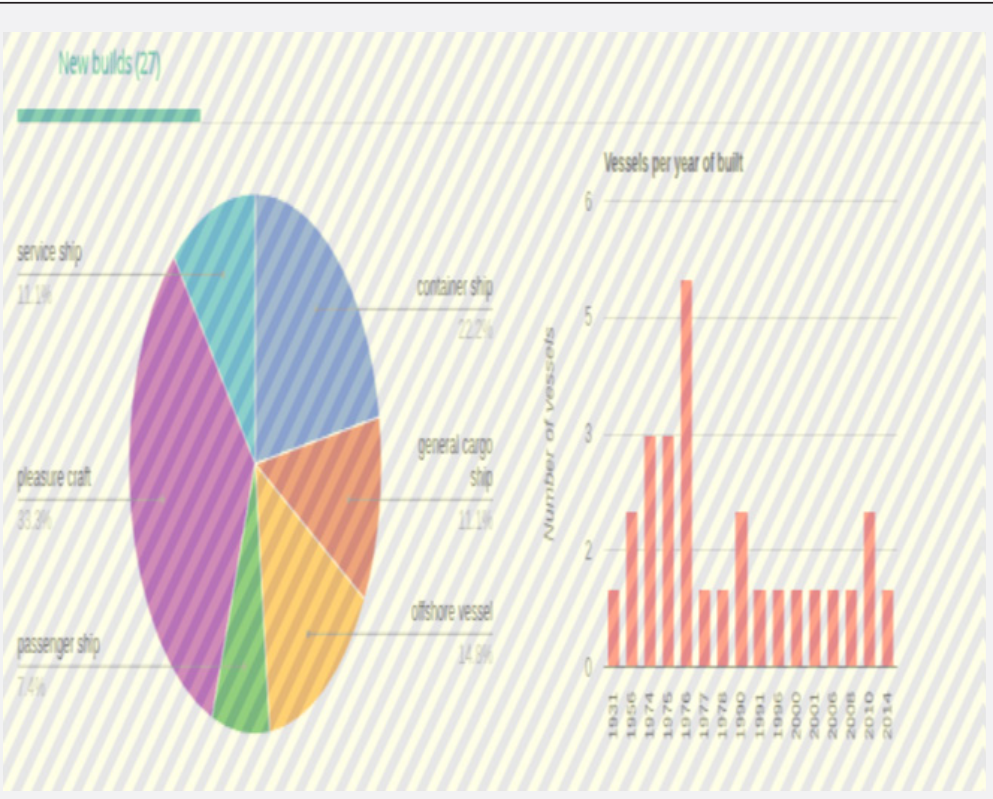

Figure 3: Productivity of the Dakar Senegal shipyard.

The shipyard in Dakar is a major nerve c enter for offshore support vessel ship repair in the West African sub region as it takes spill over vessels from Ghana and Nigeria that needs immediate repairs [5]. Most ships from Nigeria are repaired outside the country thus indicating low facility availability as well as low skilled manpower in Nigeria's maritime sector. Besides, the Carena Floating dock in Abidjan, Sierra Leone exists as a repair hub for very small vessels serving the offshore support vessel sector of Nigeria such as anchor handling tugs coming from Nigeria. Lifting capacity in the yard is however very minimal (Table 1 ).

Table 1: Shipyard facility Benchmarking for West Africa.

\begin{tabular}{|c|c|c|c|c|c|c|c|}
\hline \multirow{2}{*}{ Shipyards } & \multicolumn{2}{|c|}{ Outputs } & \multicolumn{2}{c|}{ Inputs } & \multirow{2}{*}{ weighted Output } & \multirow{2}{*}{ weighted Input } & \multirow{2}{*}{ Efficiency } \\
\cline { 2 - 5 } & Tank ER & OSV & Doc K & FDO CK & & & \\
\hline Nigerdockj & 23.80 & 60.4 & 25,000 & 3500 & 0.2897 & 6884.9412 & 0.0000 \\
\hline PSC Tema & 44.60 & 27.7 & 100,000 & 10,000 & 0.5429 & 27489.2157 & 0.0000 \\
\hline Dakar Nave & 44.10 & 7.8 & 0 & 28,000 & 0.5368 & 353.8422 & 0.0015 \\
\hline Carena Abdjan & 4.20 & 73.6 & 10,000 & 2,200 & 0.0511 & 2764.0862 & 0.0000 \\
\hline
\end{tabular}

\section{DEA Efficiency Output Scores of Major West African Shipyards}

The efficiency scores of the region's major shipyards based on available lifting capability measured in gross tons shows three shipyards on the efficiency frontier curve having scored 0.00 on the frontier curve. This shows that the three shipyards are efficient. The shipyards on the frontier are Niger-dock, Nigeria, PSC Team Shipyard Ghana and Carena Abidjan shipyard Cote D'Ivoire [6,7].

\section{Conclusion}

The development of shipyards in the West African sub region has been subjected to major drivers the chief of which is the region's major policy of local content. This has led to major upgrade of facilities in most shipyards as well as private sector involvement to enhance the efficiency and productivity of the yards. However, a lot of work remains in equipment mobilization and labor training. Efficiency scores using the BCC model of Data Envelopment Analysis showed three shipyards on the efficiency frontier curve namely Niger-dock, Nigeria, PSC Team, Ghana and Abidjan Shipyard, Cote D' Ivoire.

\section{References}

1. Clarkson (2015) Clarkson Research services, Shipping Review \& Outlook. Spring.

2. OECD (2014) Presentations delivered at the 24 November 2014 WP6 workshop on shipbuilding and the offshore industry.

3. Douglas Westwood (2015) World Deepwater Market Forecast 20152019, Douglas-Westwood.

4. NCDMB (2018) Asset Ownership: Statistical Data on Marine Vessel Utilization 2018 Data Analytics Presented By Directorate of Planning, Research and Statistics (PRS): NCDMB 
5. https://www.trusteddocks.com/shipyards/5678-psc-tema-shipyardlimited

6. https://www.trusteddocks.com/shipyards/6146-nigerdock-nigeriaplc-fze

7. https://www.trusteddocks.com/shipyards/7393-dakarnave

This work is licensed under Creative

Commons Attribution 4.0 Licens

DOI: 10.19080/OFOAJ.2020.12.555840
Your next submission with Juniper Publishers will reach you the below assets

- Quality Editorial service

- Swift Peer Review

- Reprints availability

- E-prints Service

- Manuscript Podcast for convenient understanding

- Global attainment for your research

- Manuscript accessibility in different formats ( Pdf, E-pub, Full Text, Audio)

- Unceasing customer service

Track the below URL for one-step submission https://juniperpublishers.com/online-submission.php 
